\title{
Expression of gluconeogenic enzymes and I I $\beta$-hydroxysteroid dehydrogenase type I in liver of diabetic mice after acute exercise
}

This article was published in the following Dove Press journal:

Diabetes, Metabolic Syndrome and Obesity: Targets and Therapy

21 October 2014

Number of times this article has been viewed

\author{
Korie B Brust ${ }^{1}$ \\ Kathryn A Corbell ${ }^{2}$ \\ Layla Al-Nakkash ${ }^{2}$ \\ Jeganathan Ramesh Babu ${ }^{3}$ \\ Tom L Broderick ${ }^{2,4}$ \\ 'Department of Biomedical \\ Sciences, College of Health \\ Sciences, Midwestern University, \\ Glendale, AZ, USA; ${ }^{2}$ Department of \\ Physiology, College of Osteopathic \\ Medicine, Midwestern University, \\ Glendale, AZ, USA; ${ }^{3}$ Department of \\ Nutrition, Dietetics, and Hospitality \\ Management, Auburn University, \\ Auburn, AL, USA; ${ }^{4}$ Laboratory of \\ Diabetes and Exercise Metabolism, \\ Midwestern University, Glendale, \\ AZ, USA
}

\begin{abstract}
During acute exercise, normoglycemia is maintained by a precise match between hepatic glucose production and its peripheral utilization. This is met by a complex interplay of hepatic responses and glucose uptake by muscle. However, the effect of a single bout of exercise on hepatic gluconeogenesis, corticosterone (CORT) secretion, and glucose homeostasis in the $\mathrm{db} / \mathrm{db}$ mouse model of type 2 diabetes is poorly understood. Diabetic $\mathrm{db} / \mathrm{db}$ and lean control littermates were subjected to a 30 minute session of treadmill running and sacrificed either immediately after exercise or 8 hours later. Plasma glucose levels were markedly increased in $\mathrm{db} / \mathrm{db}$ mice after exercise, whereas no change in glucose was observed in lean mice. Post-exercise measurements revealed that plasma CORT levels were also significantly increased in $\mathrm{db} / \mathrm{db}$ mice compared to lean mice. Plasma hypothalamic corticotropin releasing hormone and pituitary adrenocorticotropic hormone levels were reciprocally decreased in both $\mathrm{db} / \mathrm{db}$ and lean mice after exercise, indicating intact feedback mechanisms. Protein expression, determined by Western blot analysis, of the glucocorticoid receptor in liver was significantly increased in $\mathrm{db} / \mathrm{db}$ mice subjected to prior exercise. In liver of $\mathrm{db} / \mathrm{db}$ mice, a significant increase in the expression of phosphoenolpyruvate carboxykinase was noted compared to lean mice after exercise. However, no change in the expression of glucose-6-phosphatase (G6Pase) $\alpha$ or $\beta$ was observed in $\mathrm{db} / \mathrm{db}$ mice. Expression of $11 \beta$-hydroxysteroid dehydrogenase type 1 was increased significantly in $\mathrm{db} / \mathrm{db}$ mice compared to lean mice after exercise. Our results show differences in plasma glucose and protein expression of gluconeogenic enzymes after acute exercise between lean and diabetic $\mathrm{db} / \mathrm{db}$ mice. The $\mathrm{db} / \mathrm{db}$ diabetic mouse is hyperglycemic after acute exercise. This hyperglycemic state may be explained, in part, by enhanced endogenous CORT secretion and regulated hepatic phosphoenolpyruvate carboxykinase and $11 \beta$-hydroxysteroid dehydrogenase type 1 protein expression.
\end{abstract}

Keywords: diabetes, exercise, corticosterone, glucocorticoid receptor, PEPCK, 11ßHSD1

\section{Introduction}

Exercising on a regular basis is recommended for the treatment of diabetes mellitus and obesity because of the beneficial effects on body weight and glycemic control. Epidemiological studies have demonstrated that exercise is pivotal in reducing hyperglycemia and improving insulin sensitivity. ${ }^{1-3}$ The same benefits of exercise have been well-established in several experimental models of diabetes, including the insulin-resistant and Zucker diabetic fatty rat models of type 2 diabetes. ${ }^{4-7}$ The chronic hyperglycemia observed in these rodent models can be reversed with exercise as a result of a reduction in hepatic glucose production. ${ }^{7,8}$

During acute exercise, the liver is faced with the major challenge of providing a constant supply of glucose to the working muscle. In fact, to maintain normogly-
Correspondence: Tom L Broderick Department of Physiology, Laboratory of Diabetes and Exercise Metabolism, Midwestern University, 19555 North 59th Avenue, Glendale, AZ, 85308, USA

Tel +l 6235723664

Fax + I 6235723673

Email tbrode@midwestern.edu submit your manuscript | www.dovepress.com Dovepress

http://dx.doi.org/10.2147/DMSO.S70767 
cemia, the liver must increase its production of glucose by gluconeogenesis to precisely match peripheral glucose utilization. The effects of acute exercise on the expression of major enzymes of hepatic glucose production have been studied in the non-diabetic mouse, and as expected, adaptation to exercise involves increased expression of phosphoenolpyruvate carboxykinase (PEPCK) and glucose-6-phosphatase (G6Pase) $\alpha$ or $\beta .{ }^{9}$ In contrast, the effects of acute exercise on the transcriptional response of the gluconeogenic enzymes in liver of the $\mathrm{db} / \mathrm{db}$ mouse model of diabetes are unknown.

The $\mathrm{db} / \mathrm{db}$ mouse is a model of type 2 diabetes resulting from defective leptin receptor signaling. ${ }^{10}$ This mouse presents a phenotype that is very similar to humans diagnosed with that metabolic disorder. In addition to the gradual onset of obesity and hyperglycemia, the $\mathrm{db} / \mathrm{db}$ mouse also exhibits hypertrophy of the adrenal cortex and elevated plasma levels of corticosterone (CORT), ${ }^{11,12}$ risk factors associated with the development of insulin resistance and hyperglycemia. ${ }^{13,14} \mathrm{We}$ have shown that treadmill exercise training results is hypercortisolemia and fails to mitigate the hyperglycemia in the $\mathrm{db} / \mathrm{db}$ mouse. ${ }^{15,16}$ Based on the phenotype of the $\mathrm{db} / \mathrm{db}$ mouse as well as this maladaptation to exercise training, one might assume that the hyperglycemia seen in the $\mathrm{db} / \mathrm{db}$ mouse after exercise training may be the result of an increased glucose supply by the liver from CORT. ${ }^{11,12}$ Surprisingly, no studies have examined the effects of a single bout of acute exercise on CORT secretion and glucose homeostasis in the $\mathrm{db} / \mathrm{db}$ mouse. Therefore, the present study was designed to compare the effects of acute treadmill running on CORT secretion and hepatic expression of gluconeogenic enzymes in lean and $\mathrm{db} / \mathrm{db}$ mice. Because the glucocorticoid receptor (GR) is more abundant in the diabetic state, ${ }^{13}$ we also measured expression of this receptor in liver after acute exercise.

\section{Materials and methods Mouse model of diabetes}

The Midwestern University Institutional Animal Care and Use Committee approved this study. All animals used in this study were maintained in accordance with the recommendations in The Guide for the Care and Use of Laboratory Animals, National Institutes of Health, Publication No 85-23, 1986. Diabetic mice (C57BL/KsJ strain) were obtained from Jackson Laboratory (Bar Harbor, ME, USA) and studied at the age of 7-8 weeks. The C57BL/KsJ-lept ${ }^{d b}-$ lept $^{d b}$ mice have two mutant copies of the leptin receptor gene, which precipitates a gradual onset of hyperglycemia and obesity with subsequent hyperinsulinemia (as associated with type 2 diabetes in humans). The lean littermates, which have one mutant and one normal copy of the leptin gene $\left(\mathrm{db} /{ }^{+}\right)$, were used as controls. Mice were provided with food and water ad libitum and maintained in a room at $22^{\circ} \mathrm{C}$ with an alternating 12 hour (h) light/dark cycle.

\section{Acute exercise session}

Two series of experiments were performed. In the first series, the effects of acute exercise on blood glucose, insulin, nonesterified fatty acids (NEFA), and CORT levels in $\mathrm{db} / \mathrm{db}$ mice and lean littermates were determined. After a 1 week period of acclimatization, mice were habituated to daily activity on an electrically driven treadmill (Exer3/6; Columbus Instruments, $\mathrm{OH}, \mathrm{USA}$ ). The habituation period consisted of daily running at durations of 5-10 minutes (min) and intensities of $8-12 \mathrm{~m} / \mathrm{min}$ over a period of 5-6 days with the final habituation session conducted $48 \mathrm{~h}$ before the exercise session. Each mouse served as its own control: blood was obtained before exercise for baseline values and a repeat blood draw was obtained immediately after exercise. The acute exercise session consisted of $30 \mathrm{~min}$ at $12 \mathrm{~m} / \mathrm{min}$ at a grade of 0 degrees, followed by immediate asphyxiation induced by an atmosphere of $100 \% \mathrm{CO}_{2}$ gassing and blood collection.

In the second series of experiments aimed to determine the effects of acute exercise on protein expression of key hepatic gluconeogenic enzymes, $\mathrm{db} / \mathrm{db}$ and lean mice were randomly assigned to sedentary and exercise groups. Mice in the sedentary groups were placed on a stationary treadmill adjacent to the treadmill used for the actual running. After the acute exercise session, also consisting of $30 \mathrm{~min}$ at $12 \mathrm{~m} / \mathrm{min}$, exercised mice were returned to their cages and euthanized $8 \mathrm{~h}$ later. We chose this $8 \mathrm{~h}$ period after exercise because of previous observations that demonstrated that peak myogenic and metabolic gene expression occurs at this time. ${ }^{17}$

\section{Blood sampling and tissue collection}

In the first series of experiments, non-anesthetized mice were kept warm on a heating pad for $30 \mathrm{~min}$ before blood was obtained from a submandibular vein puncture prior to exercise. Blood was centrifuged at 3,000 rpm for $5 \mathrm{~min}$ at $4{ }^{\circ} \mathrm{C}$, and plasma was stored at $-80^{\circ} \mathrm{C}$ for subsequent measurement of NEFA, glucose (Wako Pure Chemical Industries, Ltd, Osaka, Japan), insulin (Alpco Diagnostics, Salem, NH, USA), and CORT levels (Cayman Chemical Company, Ann Arbor, MI, USA). In the second series of the experiment, blood was collected $8 \mathrm{~h}$ after acute exercise for assay of corticotrophin-releasing hormone (CRH), adrenocorticotropic hormone (ACTH), and CORT (Cayman Chemical Company) levels using standard enzyme-linked 
immunosorbent assay (ELISA) techniques as described by the manufacturer. Mice were exposed to an atmosphere of $100 \% \mathrm{CO}_{2}$, followed by thoracotomy, and blood was removed by cardiac puncture. Whole liver was removed for determination of the GR, PEPCK, 11 $\beta$-hydroxysteroid dehydrogenase (11 $\beta$-HSD) type 1 , and G6Pase $\alpha$ and $\beta$ protein expression using standard Western blot techniques.

\section{Western blot analysis of gluconeogenic proteins}

Whole liver was immediately frozen using clamps pre-cooled to the temperature of liquid nitrogen and stored at $-80^{\circ}$ for Western blot analysis. Briefly, samples were analyzed for protein content, and separated on 4\%-12\% Bis-Tris gels at 150 volts for $1.5 \mathrm{~h}$. Transfer was for $2 \mathrm{~h}$ at 30 volts on ice. Blots were incubated with primary antibody to GR (1:1000; Cell Signaling Technology, Danvers, MA, USA), PEPCK (1:200; Santa Cruz Biotechnology Inc., Dallas, TX, USA), 11 $\beta$-HSD1 (1:1000; Abcam Cambridge, MA, USA), G6Pase $\alpha$ (1:200; Santa Cruz Biotechnology Inc., Dallas, TX, USA), and G6Pase $\beta$ (1:200; Santa Cruz Biotechnology Inc.) overnight at $4^{\circ} \mathrm{C}$. To probe for actin, blots were incubated with anti-actin primary antibody (1:5000; EMD Millipore, Billerica, MA, USA) for $1 \mathrm{~h}$ at room temperature. After washing, blots were incubated with secondary antibody, anti-rabbit Immunoglobulin G (IgG) (heavy and light chains) DyLight (1:100,000; Cell Signaling Technology) and simultaneously with anti-mouse IgG $(\mathrm{H}+\mathrm{L})$ DyLight $(1: 15,000$; Cell Signaling Technology), for $1 \mathrm{~h}$ at room temperature. Images of membranes were obtained with the abundance of all proteins of interest normalized to actin, which was the internal control. Band density was analyzed using Odyssey-Clx (LI-COR, Lincoln, NE, USA) and Image Studio (LI-COR).

\section{Statistical analysis}

Data are presented as mean \pm standard error of the mean (SEM). Group mean differences were determined using analysis of variance (ANOVA), followed by the StudentNewman-Keuls comparison for post hoc analysis. Analyses were performed using GraphPad software (GraphPad Software, Inc., La Jolla, CA, USA). A value of $P<0.05$ was considered statistically significant.

\section{Results}

\section{Physical characteristics of lean and $\mathrm{db} / \mathrm{db}$ mice}

Shown in Table 1 are the characteristics of the mice used in this study. Body weight was significantly increased in $\mathrm{db} / \mathrm{db}$ mice compared to lean control mice. Associated with
Table I Basic physical characteristics of lean and diabetic db/ $\mathrm{db}$ mice

\begin{tabular}{llcl}
\hline Parameter & $\begin{array}{l}\text { Body } \\
\text { weight } \mathbf{( g )}\end{array}$ & $\begin{array}{l}\text { Liver } \\
\text { weight } \mathbf{( m g )}\end{array}$ & $\begin{array}{l}\text { Plasma } \\
\text { glucose (mg/dL) }\end{array}$ \\
\hline Lean mice & $21.2 \pm 0.4$ & $871 \pm 27$ & $164 \pm 20$ \\
$\mathrm{db} / \mathrm{db}$ mice & $30.8 \pm 0.7^{*}$ & $1,714 \pm 10 \mathrm{I}^{*}$ & $420 \pm 19^{*}$ \\
\hline
\end{tabular}

Notes: Body weight represents combined weight of mice from series I and 2. Liver weight is representative of mice from series 2 that were euthanized 8 hours after acute exercise. Plasma for the measurement of glucose was obtained in mice prior to exercise in series I. Values are expressed as mean \pm SEM. $* P<0.001$ compared to lean mice.

Abbreviation: SEM, standard error of the mean.

increased body weight of $\mathrm{db} / \mathrm{db}$ mice was a significantly greater liver weight. Further, the concentration of glucose in the plasma of $\mathrm{db} / \mathrm{db}$ mice, as expected, was increased compared to lean mice.

\section{Plasma levels of glucose, insulin, NEFA, and CORT in mice after exercise}

To evaluate the effects of one bout of exercise on selected plasma parameters, $\mathrm{db} / \mathrm{db}$ mice ran on the treadmill for $30 \mathrm{~min}$. Plasma levels of glucose, insulin, NEFA, and CORT in mice before (basal) and after the exercise (post-exercise) session are shown in Figures 1 and 2. Plasma levels of glucose and insulin were significantly higher in $\mathrm{db} / \mathrm{db}$ mice compared to lean mice under basal conditions, confirming the diabetic state (Figure 1). After 30 min of acute exercise, plasma levels of glucose and insulin were unchanged in lean mice. In $\mathrm{db} / \mathrm{db}$ mice, however, exercise resulted in a significant increase in the plasma levels of glucose, whereas plasma insulin levels were decreased compared to the basal state. Plasma levels of CORT were also significantly higher in $\mathrm{db} / \mathrm{db}$ mice compared to lean mice before exercise, whereas no differences in plasma NEFA were observed between groups (Figure 2). In lean mice, plasma levels of NEFA were unchanged after exercise whereas a significant increase was noted in $\mathrm{db} / \mathrm{db}$ mice. Plasma CORT levels were increased in both lean and diabetic mice after exercise.

\section{Plasma levels of CRH, ACTH, and CORT in $\mathrm{db} / \mathrm{db}$ mice $8 \mathrm{~h}$ after exercise}

Plasma hormone levels of the hypothalamus-pituitary adrenal axis (HPA) obtained $8 \mathrm{~h}$ after acute exercise are shown in Figure 3. Plasma levels of CORT were significantly higher in $\mathrm{db} / \mathrm{db}$ mice compared to lean mice. Prior exercise also significantly increased plasma levels of CORT in $\mathrm{db} / \mathrm{db}$ mice. However, in lean mice subjected to prior exercise, plasma CORT levels were not significantly increased. As expected, and consistent with negative feedback control by 

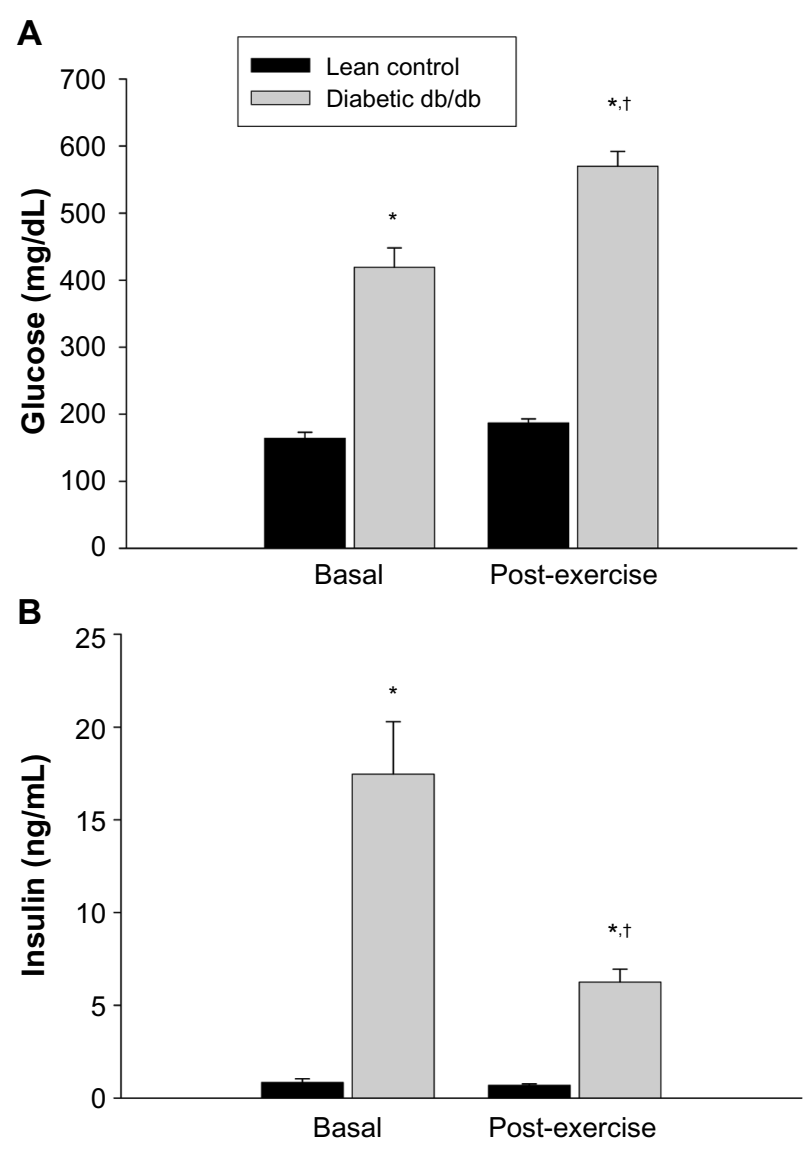

Figure I Effect of a 30 minute bout of exercise on plasma glucose (A) and insulin (B) in $\mathrm{db} / \mathrm{db}$ mice.

Notes: Plasma measurements were obtained immediately after exercise. Values are reported as a mean \pm standard error of the mean for ten mice in each group. $* P<0.05$ compared to lean control; ${ }^{\dagger} P<0.05$ compared to basal conditions.

CORT, plasma ACTH levels (Figure 3B) were reciprocally decreased in both lean and $\mathrm{db} / \mathrm{db}$ mice, regardless of exercise. A significant decrease in plasma levels of hypothalamic CRH was observed in sedentary $\mathrm{db} / \mathrm{db}$ mice and in $\mathrm{db} / \mathrm{db}$ mice after exercise (data not shown).

\section{Protein expression of hepatic GR, gluconeogenic enzymes and II $\beta$-HSDI after exercise in mice}

Expression of the hepatic proteins of interest measured $8 \mathrm{~h}$ after exercise is shown in Figures 4 to 8. GR expression was not altered by prior exercise in lean mice. However, compared to lean mice, a significant increase in GR expression was observed in $\mathrm{db} / \mathrm{db}$ mice subjected to exercise (Figure 4). Also accompanying the increase in GR expression in $\mathrm{db} / \mathrm{db}$ mice was a significant increase in PEPCK expression (Figure 5). However, no change in PEPCK protein expression was observed in lean mice subjected to exercise. Interestingly, as shown in Figures 6 and 7, neither the

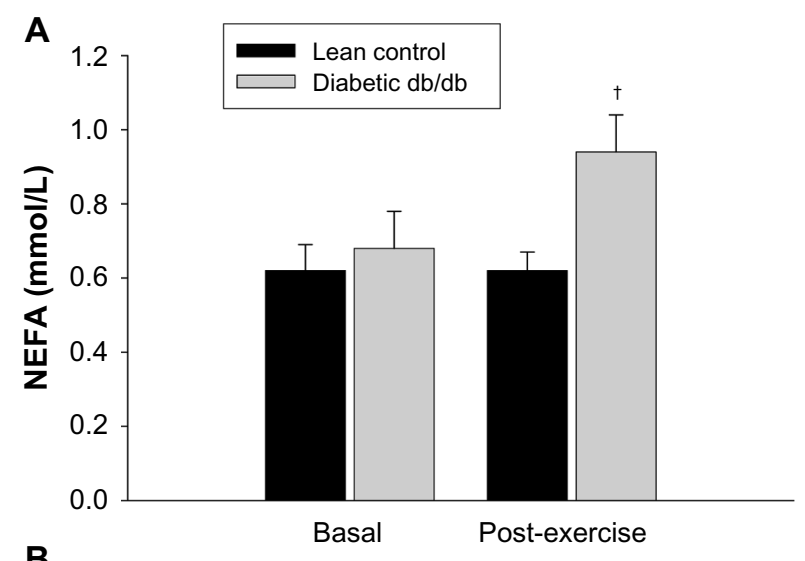

B

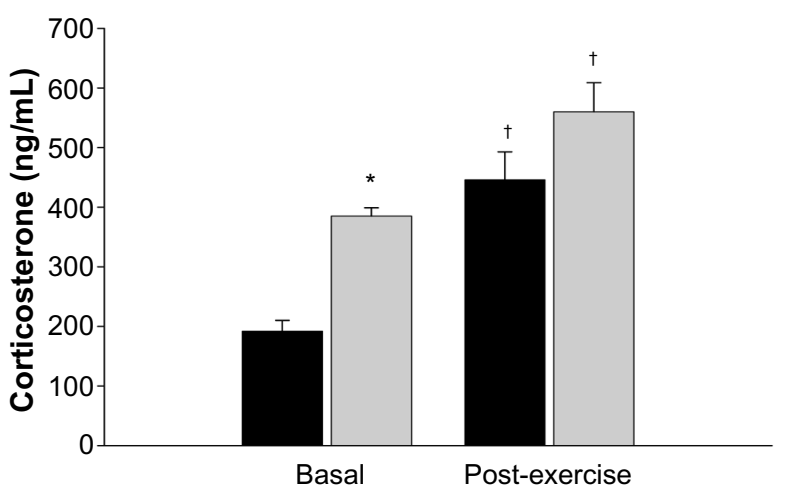

Figure 2 Effect of a 30 minute bout of exercise on plasma NEFA (A) and corticosterone $(\mathbf{B})$ in $\mathrm{db} / \mathrm{db}$ mice.

Notes: Plasma measurements were obtained immediately after exercise. Values are reported as a mean \pm standard error of the mean for ten mice in each group. $* P<0.05$ compared to lean control; ${ }^{\dagger} P<0.05$ compared to basal conditions.

Abbreviation: NEFA, non-esterified fatty acids.

diabetic state nor exercise induced changes in the expression of G6Pase. Expression of 11ß-HSD1, the key enzyme that converts inactive CORT to active CORT, and regulating access to the GR, was significantly increased in $\mathrm{db} / \mathrm{db}$ mice compared to lean mice. Although expression of 11ß-HSD1 remained increased in $\mathrm{db} / \mathrm{db}$ mice after exercise compared to the lean mice (Figure 8), a 21\% decrease in the expression of the protein was observed in these mice after exercise. In summary, plasma levels of CORT remained higher in $\mathrm{db} / \mathrm{db}$ mice compared to lean mice $8 \mathrm{~h}$ after acute exercise. During this period, expression of hepatic GR, PEPCK, and 11ß-HSD1 was significantly increased in $\mathrm{db} / \mathrm{db}$ mice compared to lean mice after exercise.

\section{Discussion}

The results of this present study demonstrate that differences exist between lean and diabetic $\mathrm{db} / \mathrm{db}$ mice in the secretion of CORT and expression of proteins that regulate hepatic gluconeogenesis following an acute session of treadmill running. Compared to lean mice, the main findings after 

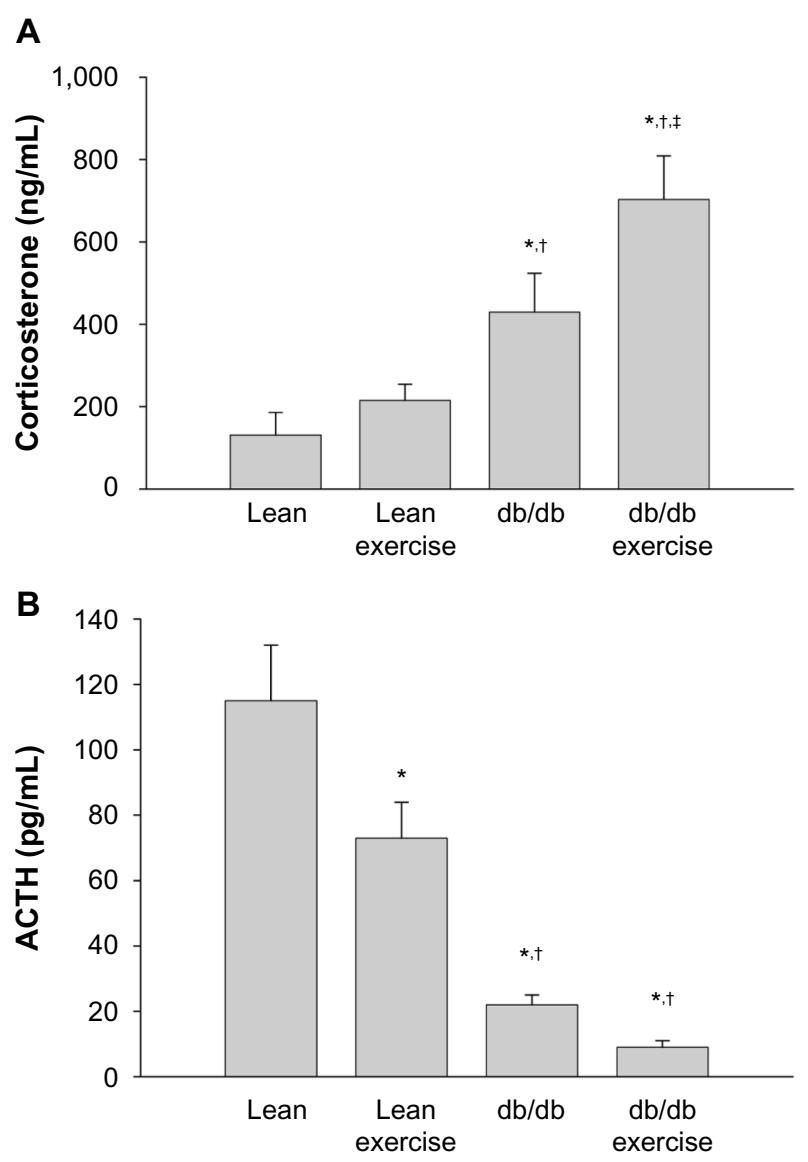

Figure 3 Plasma levels of corticosterone (A) and adrenocorticotropic hormone $($ ACTH) (B) measured 8 hours after acute exercise in $\mathrm{db} / \mathrm{db}$ mice.

Notes: Values are reported as a mean \pm standard error of the mean for 6-9 mice in each group. $* P<0.05$ compared to lean control; ${ }^{\dagger} P<0.05$ compared to lean exercise mice; ${ }^{\ddagger} \mathrm{P}<0.05$ compared to $\mathrm{db} / \mathrm{db}$ mice.

30 mins of treadmill running could be summarized as follows. Firstly, an acute bout of exercise induces a state of hyperglycemia in $\mathrm{db} / \mathrm{db}$ mice. Secondly, acute exercise increases CORT secretion in both lean and $\mathrm{db} / \mathrm{db}$ mice. However, this effect is sustained and persists for a period of $8 \mathrm{~h}$ after exercise in $\mathrm{db} / \mathrm{db}$ mice only. And lastly, liver of $\mathrm{db} / \mathrm{db}$ mice demonstrates increased protein expression of the PEPCK, GR, and 11 $\beta$-HSD $18 \mathrm{~h}$ after acute exercise. Our results, therefore, suggest that a number of potential mechanisms relating to hepatic gluconeogenesis exist to explain the hyperglycemia observed in the $\mathrm{db} / \mathrm{db}$ mouse after exercise. It is possible that acute exercise by increasing endogenous CORT secretion may further increase the expression of PEPCK by acting through the GR. The hyperglycemic response in the $\mathrm{db} / \mathrm{db}$ mouse may also be explained indirectly by the enhanced expression of $11 \beta-H S D 1$, which would increase hepatic CORT levels. These differences in protein expression in liver of lean and $\mathrm{db} / \mathrm{db}$ mice were expected considering that CORT secretion was enhanced in $\mathrm{db} / \mathrm{db}$ mice under basal conditions, and was further increased with exercise as well as during the $8 \mathrm{~h}$ period after the exercise session. ${ }^{11,12}$ We chose the $\mathrm{db} / \mathrm{db}$ mouse because of the close phenotypic resemblance of the mouse metabolic disorder and human type 2 diabetes. $\mathrm{The} \mathrm{db} / \mathrm{db}$ mouse exhibits defective leptin receptor signaling, resulting in leptin resistance and hyperleptinemia. ${ }^{10}$ This is rarely a cause of diabetes in humans but is nonetheless reported in diabetes and obesity. ${ }^{18}$ Interestingly, recent evidence indicates that leptin treatment to uncontrolled steptozotocin-diabetic rats normalized plasma glucose and CORT levels by decreasing rates of hepatic gluconeogenesis, suggesting a role for leptin in regulating HPA function and glucose production. ${ }^{19}$

Human studies show that excess endogenous glucocorticoid production is diabetogenic in nature, leading to visceral adiposity, insulin resistance, and increased glucose output from the liver. ${ }^{20}$ Excess production of glucocorticoids is also linked, in part, to the development of hyperglycemia and insulin resistance in the $\mathrm{db} / \mathrm{db}$ mouse. ${ }^{12,21}$ Our results showed that acute exercise increased CORT release and that endogenous CORT production remained elevated in the $\mathrm{db} / \mathrm{db}$ mouse for a period of at least $8 \mathrm{~h}$ after exercise. The observation that acute exercise further worsened the hyperglycemic state in the $\mathrm{db} / \mathrm{db}$ mouse is consistent with the role of CORT in glucose metabolism. Elevated circulating CORT in exercising mice can be the result of an increased central drive from the HPA or increased peripheral activation of glucocorticoids though $11 \beta$-HSD1 expression, or both. ${ }^{22}$ The data shown in the current study suggest that the increase in CORT in $\mathrm{db} / \mathrm{db}$ mice after exercise is not caused by direct stimulation of the HPA since ACTH levels were reciprocally decreased in the presence of high plasma CORT levels, indicating no disruption in feedback regulation. It is possible that the source of the excess CORT originates from a hypertrophied adrenal cortex, although this is a structural change that is known to occur in response to chronic forced treadmill training. ${ }^{23}$ Similarly, earlier studies suggest that excess endogenous CORT production is due to hyper-secretion of ACTH, although this is age-dependent and occurring only in older obese-hyperglycemic mice. ${ }^{11,24}$

Another important finding of this study is the effect of the diabetic state on 11 $\beta$-HSD1 expression. ${ }^{8}$ The up-regulation of $11 \beta-H S D 1$ protein in liver of $\mathrm{db} / \mathrm{db}$ mice is consistent with the hypercortisolemia seen in this model. Increased expression of $11 \beta-H S D 1$ is known to increase the local exposure to the glucocorticoid pool in rodents, by converting inactive 11-dehydrocorticosterone to active CORT. Overexpression of 11ß-HSD1 in mice has been linked to visceral adipose tissue accumulation and increases in hepatic gluconeogenesis, 

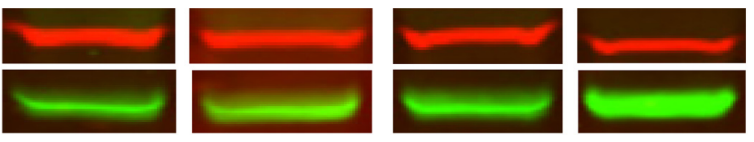

Actin: $43 \mathrm{kDa}$

GR: $94 \mathrm{kDa}$

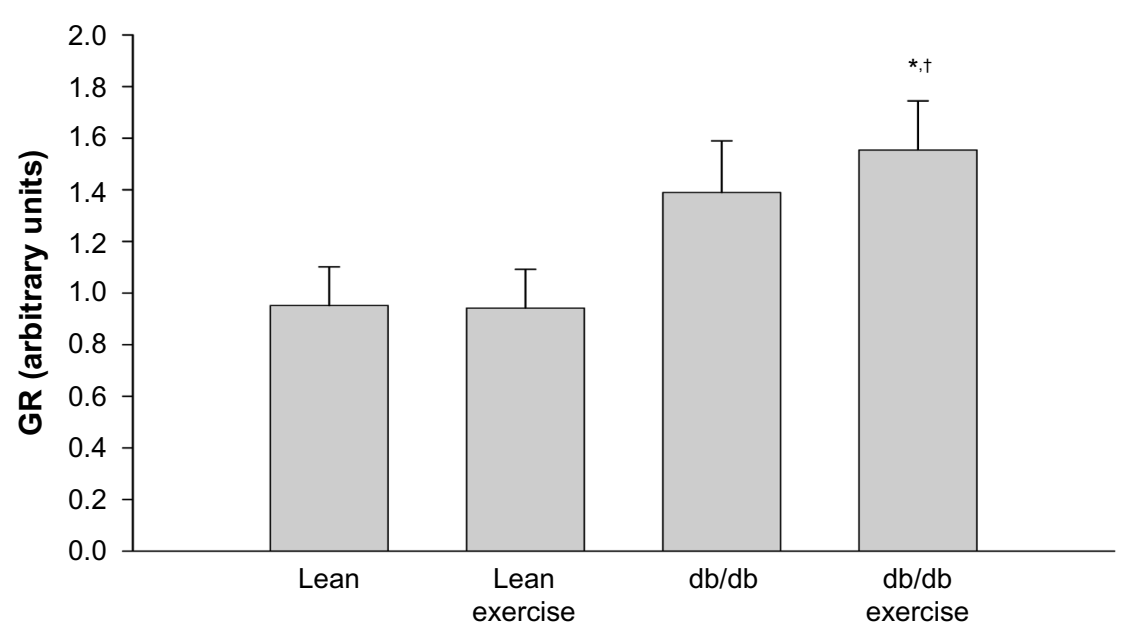

Figure 4 Hepatic protein expression of the glucocorticoid receptor (GR) measured 8 hours after acute exercise in $\mathrm{db} / \mathrm{db}$ mice.

Notes: Values are reported as a mean \pm standard error of the mean for 6-9 mice in each group, and normalized to internal control. $* P<0.05$ compared to lean control; $t \mathrm{P}<0.05$ compared to lean exercise mice.

hyperglycemia, and insulin resistance in skeletal muscle. ${ }^{25-27}$ The increased expression of 11ß-HSD1 in liver along with increased plasma glucose levels in $\mathrm{db} / \mathrm{db}$ mice is consistent with the role of $11 \beta-H S D 1$ in providing an indirect source of glucose. However, we observed a tendency for protein expression to be lower $(\sim 21 \%)$ in $\mathrm{db} / \mathrm{db}$ mice after acute exercise. The relevance for this decrease in hepatic $11 \beta$-HSD1 protein expression after acute exercise is not clear. It is possible that this may confer protection against tissue elevations in CORT, but the metabolic implications of this decrease in 11ß-HSD1 protein expression are gleaned from chronic training studies. Indeed, endurance running studies in the Syrian hamster have demonstrated significant decreases in the expression of $11 \beta$-HSD1 in skeletal muscle and liver, ${ }^{28}$ resulting in beneficial effects such as improved insulin sensitivity, decreased visceral adipose tissue obesity, and reduced hepatic gluconeogenesis. ${ }^{29}$

Liver of $\mathrm{db} / \mathrm{db}$ mice responded to exercise whereas this was not the case in liver of non-diabetic mice. The reasons for these differences in the expression of hepatic proteins

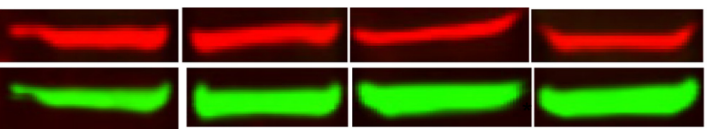

Actin: $43 \mathrm{kDa}$

PEPCK: $62 \mathrm{kDa}$

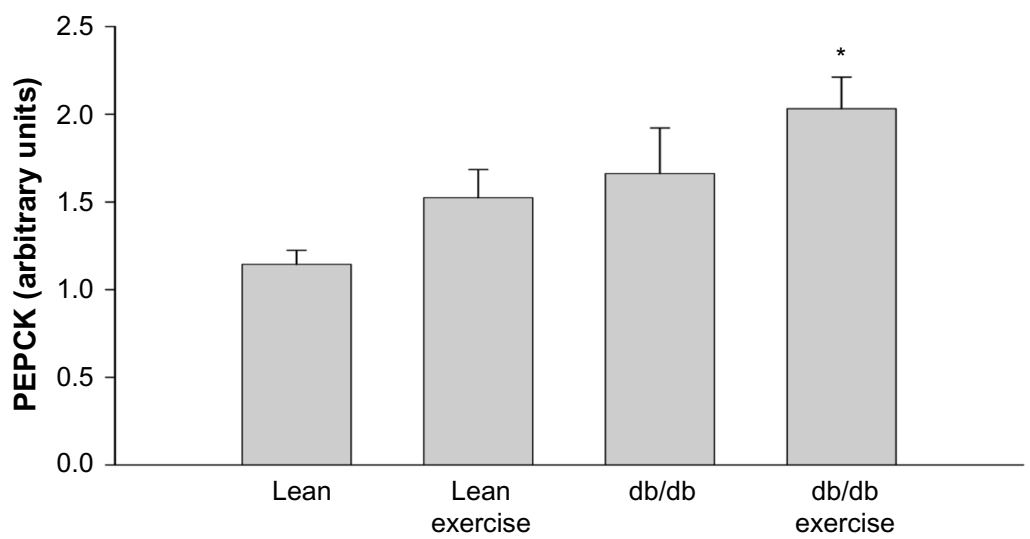

Figure 5 Hepatic protein expression of phosphoenolpyruvate carboxykinase (PEPCK) measured 8 hours after acute exercise in $\mathrm{db} / \mathrm{db}$ mice.

Notes: Values are reported as a mean \pm standard error of the mean for 6-9 mice in each group, and normalized to internal control. $* P<0.05$ compared to lean control. 

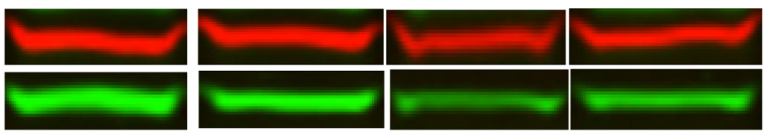

Actin: $43 \mathrm{kDa}$

G6Pase $\alpha: 36 \mathrm{kDa}$

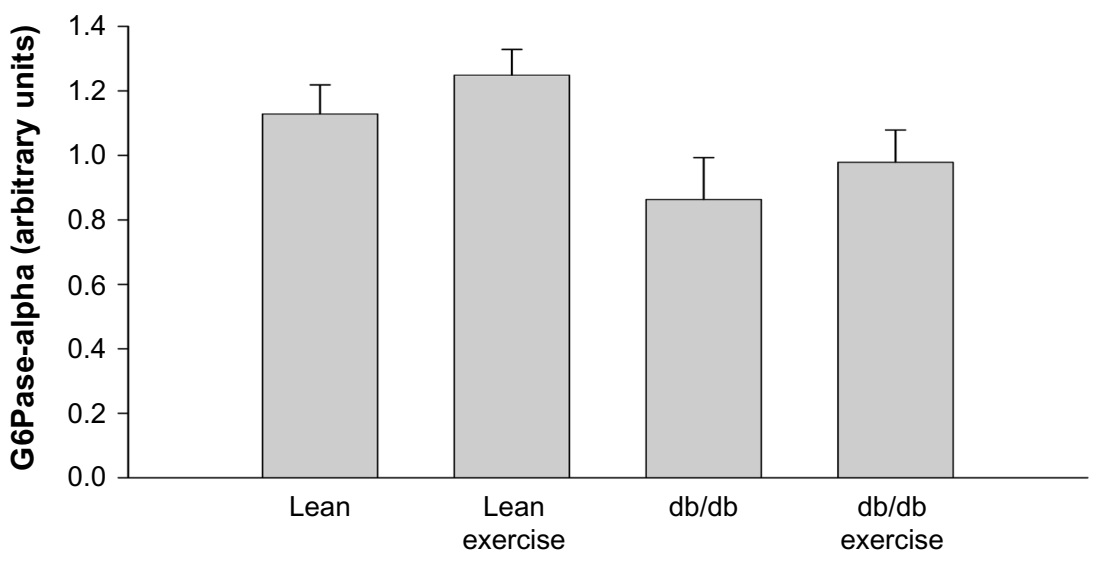

Figure 6 Hepatic protein expression of glucose-6-phosphatase $\alpha$ (G6Pase $\alpha$ ) measured 8 hours after acute exercise in $\mathrm{db} / \mathrm{db}$ mice. Notes: Values are reported as a mean \pm standard error of the mean for 6-9 mice in each group, and normalized to internal control.

between non-diabetic and diabetic mice are unknown. One could speculate that the intensity of the exercise bout $\left(12 \mathrm{~m} / \mathrm{min}^{-1}\right)$ was not sufficient to induce a transcriptional response in non-diabetic mice. This is supported by a recent study in which a weak and insignificant expression of PEPCK messenger RNA was reported in C57BL/6 mice immediately after $60 \mathrm{~min}$ of exercise at $14 \mathrm{~m} / \mathrm{min}^{-1}$, which was accompanied by a modest decrease in liver glycogen content. ${ }^{9}$ In contrast, an up-regulation of G6Pase messenger RNA content in liver was observed under the same exercise conditions, ${ }^{9}$ suggesting that its expression may peak early during recovery. We did not study the time course of hepatic protein expression after exercise, but based on these observations, it is clear that proteins are differentially expressed and influenced by the intensity of exercise, the time elapsed after exercise, and the presence of diabetes.

An important question which arises from this study is what is the role of hepatic glycogenolysis on glucose homeostasis during acute exercise in $\mathrm{db} / \mathrm{db}$ mice? Acute exercise reduces liver glycogen content and this is associated with an increase in glucose output by the liver to meet energy demands. ${ }^{30}$ The increased glucagon/insulin
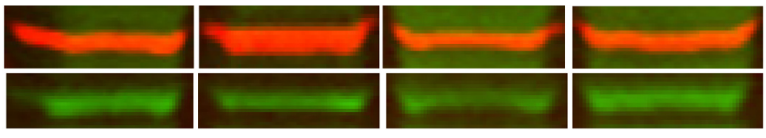

Actin: $43 \mathrm{kDa}$

G6Pase $\beta: 34 \mathrm{kDa}$

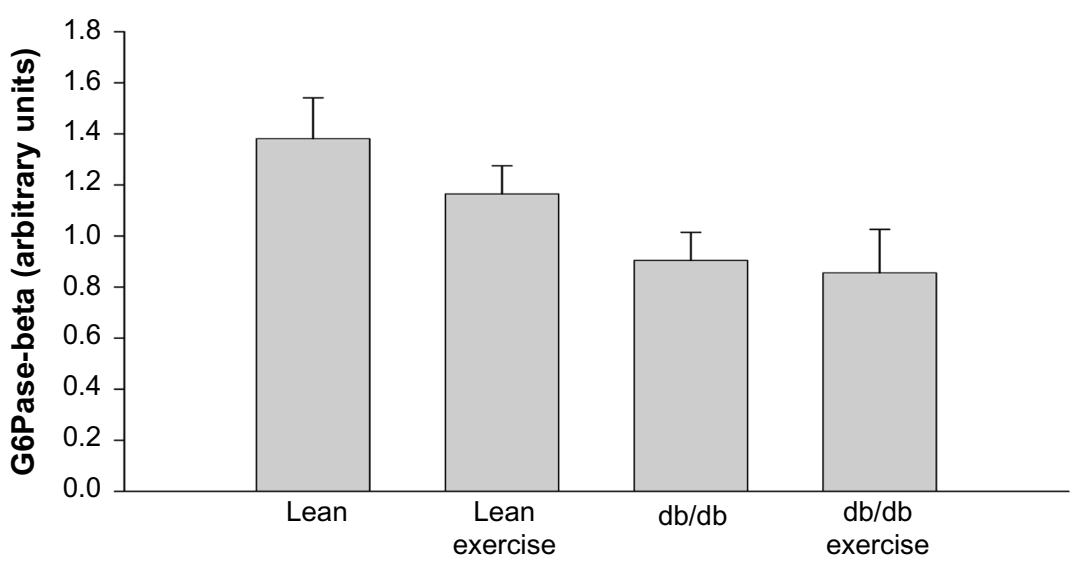

Figure 7 Hepatic protein expression of glucose-6-phosphatase $\beta$ (G6Pase $\beta$ ) measured 8 hours after acute exercise in $\mathrm{db} / \mathrm{db}$ mice. Notes: Values are reported as a mean \pm standard error of the mean for 6-9 mice in each group, and normalized to internal control. 

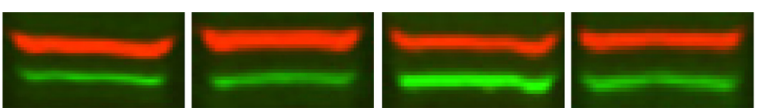

Actin: $43 \mathrm{kDa}$

HSD: $32 \mathrm{kDa}$

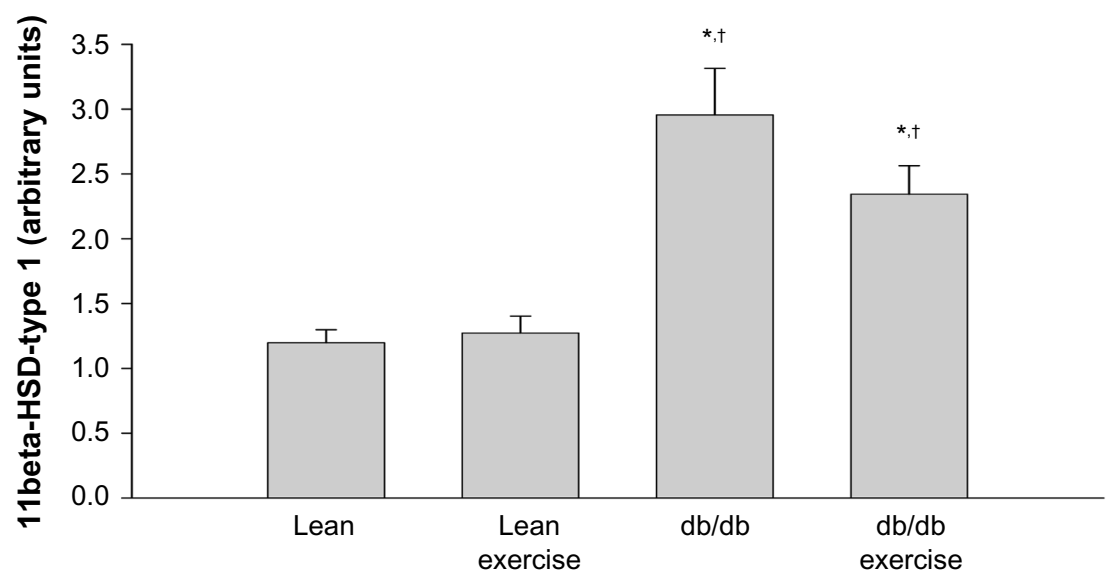

Figure 8 Hepatic protein expression of I I $\beta$-hydroxysteroid dehydrogenase type I (I I $\beta$-HSD type I) measured 8 hours after acute exercise in db/db mice. Notes: Values are reported as a mean \pm standard error of the mean for 6-9 mice in each group, and normalized to internal control. $* P<0.05$ compared to lean control; ${ }^{\dagger} \mathrm{P}<0.05$ compared to lean exercise mice.

ratio and effect of catecholamines are also associated with increased rates of hepatic glycogenolysis during exercise, ${ }^{31}$ changes that appear to have been detected in $\mathrm{db} / \mathrm{db}$ mice based solely on the decrease in insulin secretion. These are important metabolic signals contributing to overall plasma glucose homeostasis during exercise, and demonstrated in rodents and diabetes. ${ }^{30,32,33}$ Further, alterations in hepatic glycogenolysis are dependent on the exercise protocol with pronounced changes occurring with a greater duration and intensity of running. ${ }^{30}$ Hence, it could be argued that the hepatic response and hyperglycemia detected during exercise in the $\mathrm{db} / \mathrm{db}$ mouse, compared to the lean mouse, is also explained by the increased metabolic demand of the obese state of $\mathrm{db} / \mathrm{db}$ mice. A decrease in insulin secretion and an increase in plasma NEFA was observed only in $\mathrm{db} / \mathrm{db}$ mice, indicating a more exhaustive response to exercise compared to lean mice. Clearly, the effect of exercise on hepatic glycogenolysis and the exact transcriptional responses in this model of type 2 diabetes need to be investigated.

A hyperglycemic response during acute submaximal exercise may be viewed as a perturbation in glucose control worsening the diabetic state and alleviating any possible benefit of exercise. In the $\mathrm{db} / \mathrm{db}$ mouse, however, this response to exercise can be considered as an abnormal feature unique to this model for the following reasons. First, the $\mathrm{db} / \mathrm{db}$ mouse is leptin resistant, and leptin treatment to leptin-deficient ob/ob mice, a model that also displays obesity and hyperglycemia, results in increased ambulatory and running wheel activity, and increased energy expenditure. ${ }^{34}$ In addition, several studies have indicated that low intensity wheel or treadmill running improves cardiovascular and metabolic risk factors in absence of any improvement on obesity or hyperglycemia. ${ }^{35-38}$

In conclusion, the results of this study show that CORT secretion and hepatic protein expression of PEPCK, GR, and $11 \beta$-HSD1 are elevated following one session of acute exercise in diabetic $\mathrm{db} / \mathrm{db}$ mice, and thus may contribute to the hyperglycemia in this model of type 2 diabetes. The role of hepatic glycogenolysis should be considered as a factor also contributing to hyperglycemia during exercise in the $\mathrm{db} / \mathrm{db}$ mouse.

\section{Acknowledgments}

This study was supported by grants from the College of Health Sciences Graduate Education Program (KBB), Midwestern University Office of Research and Sponsored Programs (TLB, LA) and the Diabetes Action Research and Education Foundation (TLB).

\section{Disclosure}

The authors have no conflicts of interest to disclose.

\section{References}

1. Diabetes Prevention Program Research Group. Reduction of the incidence of type 2 diabetes with lifestyle intervention or metformin. $N E n g l$ J Med. 2002;346:393-403.

2. Boule NG, Haddad E, Kenny GP, Wells GA, Sigal RJ. Effects of exercise on glycemic control and body mass in type 2 diabetes mellitus: a meta-analysis of controlled clinical trials. JAMA. 2001;286(10):1218-1227. 
3. Tuomilehto J, Lindstrom J, Eriksson JG, et al. Prevention of type 2 diabetes mellitus by changes in lifestyle among subjects with impaired glucose tolerance. $N$ Engl J Med. 2001;344(18):1343-1350.

4. Cortez MY, Torgan CE, Brozinick JT Jr, Ivy JL. Insulin resistance of obese Zucker rats exercise trained at two different intensities. Am J Physiol. 1991;261(5 Pt 1):E613-E619.

5. Banks EA, Brozinick JT Jr, Yaspelkis BB 3rd, Kang HY, Ivy JL. Muscle glucose transport, GLUT-4 content, and degree of exercise training in obese Zucker rats. Am J Physiol. 1992;263(5 Pt 1):E1010-E1015.

6. Davidoff AJ, Mason MM, Davidson MB, et al. Sucrose-induced cardiomyocyte dysfunction is both preventable and reversible with clinically relevant treatments. Am J Physiol Endocrinol Metab. 2004;286(5):E718-E724.

7. Chang SP, Chen YH, Chang WC, Liu IM, Cheng JT. Merit of physical exercise to reverse the higher gene expression of hepatic phosphoenolpyruvate carboxykinase in obese Zucker rats. Life Sci. 2006;79(3):240-246.

8. Campbell JE, Király MA, Atkinson DJ, D'souza AM, Vranic M, Riddell MC. Regular exercise prevents the development of hyperglucocorticoidemia via adaptations in the brain and adrenal glands in male Zucker diabetic fatty rats. Am J Physiol Integr Comp Physiol. 2010;299(1):R168-R176.

9. Hoene M, Lehmann R, Hennige AM, et al. Acute regulation of metabolic genes and insulin receptor substrates in the liver of mice by one single bout of treadmill exercise. J Physiol. 2009;587(Pt 1):241-252.

10. Leibel RL, Chung WK, Chua SC Jr. The molecular genetics of rodent single gene obesities. J Biol Chem. 1997;272(51):31937-31940.

11. Naeser P. Adrenal function in the diabetic mutant mouse (gene symbol dbm). Acta Physiol Scand. 1976;98(4):395-399.

12. Coleman DL, Burkart DL. Plasma corticosterone concentrations in diabetic (db) mice. Diabetologia. 1977;13(1):25-26.

13. Perelló M, Moreno G, Gaillard RC, Spinedi E. Glucocorticoid-dependency of increased adiposity in a model of hypothalamic obesity. Neuro Endocrinol Lett. 2004;25(1-2):119-126.

14. Masuzaki H, Ogawa Y, Hosoda K, et al. Glucocorticoid regulation of leptin synthesis and secretion in humans: elevated plasma leptin levels in Cushing's syndrome. J Clin Endocrinol Metabol. 1997;82(8):2542-2547.

15. Sennott J, Morrissey J, Standley PR, Broderick TL. Treadmill exercise training fails to restore defects in glucose, insulin and muscle glut 4 content in the $\mathrm{db} / \mathrm{db}$ mouse model of diabetes. Pathophysiology. 2008;15(3):173-179.

16. Parrott CR, Ghosh P, Tedeschi J, Gunasekara G, Broderick TL. Urinary corticosterone and normetanephrine levels after voluntary wheel and forced treadmill running in the $\mathrm{db} / \mathrm{db}$ mouse. Journal of Diabetes Mellitus. 2011;1:71-78.

17. Yang Y, Creer A, Jemiolo B, Trappe S. Time course of myogenic and metabolic gene expression in response to acute exercise in human skeletal muscle. J Appl Physiol (1985). 2005;98(5):1745-1752.

18. Bray GA, York DA. Clinical review 90: Leptin and clinical medicine: a new piece in the puzzle of obesity. J Clin Endocrinol Metab. 1997;82(9):2771-2776.

19. Perry RJ, Zhang XM, Zhang D, et al. Leptin reverses diabetes by suppression of the hypothalamic-pituitary-adrenal axis. Nat Med. 2014;20(7):759-763.

20. Andrews RC, Walker BR. Glucocorticoids and insulin resistance: old hormones, new targets. Clin Sci (Lond). 1999;96(5):513-523.

21. Rosmond R, Dallman MF, Bjorntorp P. Stress-related cortisol secretion in men: relationships with abdominal obesity and endocrine, metabolic and hemodynamic abnormalities. J Clin Endocrinol Metab. 1998;83(6):1853-1859.
22. Anagnostis P, Athyros VG, Tziomalos K, Karagiannis A, Mikhailidis DP. Clinical review: The pathogenetic role of cortisol in the metabolic syndrome: a hypothesis. J Clin Endocrinol Metab. 2009;94(8):2692-2701.

23. Moraska A, Deak T, Spencer RL, Roth D, Fleshner M. Treadmill running produces both positive and negative physiological adaptations in Sprague-Dawley rats. Am J Physiol Regul Integr Comp Physiol. 2000;279(4):R1321-R1329.

24. Naeser P. Structure of the adrenal glands in mice with the obesehyperglycaemic syndrome (gene symbol ob). Acta Pathol Microbiol Scand A. 1975;83(1):120-126.

25. Masuzaki H, Paterson J, Shinyama H, et al. A transgenic model of visceral obesity and the metabolic syndrome. Science. 2001;294(5549): 2166-2170.

26. Liu Y, Nakagawa Y, Wang Y, et al. Increased glucocorticoid receptor and 11 beta\}-hydroxysteroid dehydrogenase type 1 expression in hepatocytes may contribute to the phenotype of type 2 diabetes in $\mathrm{db} /$ db mice. Diabetes. 2005;54(1):32-40.

27. Whorwood CB, Donovan SJ, Flanagan D, Phillips DI, Byrne CD Increased glucocorticoid receptor expression in human skeletal muscle cells may contribute to the pathogenesis of metabolic syndrome. Diabetes. 2002;51(4):1066-1075.

28. Coutinho AE, Campbell JE, Fediuc S, Riddell MC. Effect of voluntary exercise on peripheral tissue glucocorticoid receptor content and the expression and activity of $11 \beta$-HSD1 in the Syrian hamster. $J$ Appl Physiol (1985). 2005;100(5):1483-1488.

29. Kargi AY, Iacobellis G. Adipose Tissue and Adrenal Glands: Novel Pathophysiological Mecahnisms and Clinical Applications. Int J Endocrinol. 2014;2014:614074

30. Kjaer M. Hepatic glucose production during exercise. Adv Exp Med Biol. 1998;441:117-127.

31. Wasserman DH, Spalding JA, Lacy DB, Colburn CA, Goldstein RE, Cherrington AD. Glucagon is a primary controller of hepatic glycogenolysis and gluconeogenesis during muscular work. Am J Physiol. 1989;257(1 Pt 1):E108-E117.

32. Petersen KF, Price TB, Bergeron R. Regulation of net hepatic glycogenolysis and gluconeogenesis during exercise: impact of type 1 diabetes. $J$ Clin Endocrinol Metab. 2004;89(9):4656-4664.

33. Borba-Murad GR, de Souza HM, Lopes G, Ferreira EB, Dambroso D, Bazotte RB. Changes in glycemia induced by exercise in rats: contribution of hepatic glycogenolysis and gluconeogenesis. Res Commun Mol Pathol Pharmacol. 1998;102(2):113-123.

34. Morton GJ, Kaiyala KJ, Fisher JD, Ogimoto K, Scharwtz MW, Wisse BE. Identification of a physiological role for leptin in the regulation of ambulatory activity and wheel running in mice. Am J Phsyiol Endocrinol Metab. 2011;300(2):E392-E401.

35. Broderick TL, Parrott CR, Wang D, Jankowski M, Gutkowska J. Expression of cardiac GATA4 and downstream genes after exercise training in the $\mathrm{db} / \mathrm{db}$ mouse. Pathophysiology. 2012;19(3):193-203.

36. Esser KA, Su W, Matveev S, et al. Voluntary wheel running ameliorates vascular smooth muscle hypercontractility in type 2 diabetic $\mathrm{db} / \mathrm{db}$ mice. Appl Physiol Nutr Metab. 2007;32(4):711-720.

37. Gutkowska J, Broderick TL, Bogdan D, Wang D, Lavoie JM, Jankowski M. Downregulation of oxytocin and natriuretic peptides in diabetes: possible implications in cardiomyopathy. $J$ Physiol. 2009;587(Pt 19):4725-4736.

38. Moien-Afshari F, Ghosh S, Elmi S, et al. Exercise restores endothelia function independently of weight loss or hyperglycaemic status in $\mathrm{db} / \mathrm{db}$ mice. Diabetologia. 2008;51(7):1327-1337. 
Diabetes, Metabolic Syndrome and Obesity: Targets and Therapy

Dovepress

\section{Publish your work in this journal}

Diabetes, Metabolic Syndrome and Obesity: Targets and Therapy is opinion and commentaries are all considered for publication. The an international, peer-reviewed open-access journal committed to the rapid publication of the latest laboratory and clinical findings in the fields of diabetes, metabolic syndrome and obesity research. Original research, review, case reports, hypothesis formation, expert manuscript management system is completely online and includes a very quick and fair peer-review system, which is all easy to use. Visit http://www.dovepress.com/testimonials.php to read real quotes from published authors.

Submit your manuscript here: http://www.dovepress.com/diabetes-metabolic-syndrome-and-obesity-targets-and-therapy-journal 